\title{
Knowledge, Attitude and Practice Towards Malaria and Associated Factors in Areka Town, Southern Ethiopia: Community-Based Cross- Sectional Study
}

Deresse Legesse Kebede*, Desalegn Tsegaw Hibstu, Betelhem Eshetu Birhanu and Fanuel Belayneh Bekele

School of Public and Environmental Health, College of Medicine and Health Sciences, Hawassa University, Ethiopia

${ }^{*}$ Corresponding author: Kebede DL, School of Public and Environmental Health, College of Medicine and Health Sciences, Hawassa University, Ethiopia, Tel: +251933539021; E-mail: delhsaw@gmail.com

Received date: June 29, 2017; Accepted date: July 19, 2017; Published date: July 28, 2017

Copyright: @ 2017 Kebede DL, et al. This is an open-access article distributed under the terms of the Creative Commons Attribution License, which permits unrestricted use, distribution, and reproduction in any medium, provided the original author and source are credited.

\begin{abstract}
Background: Understanding knowledge level, perception towards and practical behaviors of individuals and communities is crucial to ensure appropriate intervention measures. However, comprehensive knowledge, perception and practice of the community on malaria is not investigated in the study area.
\end{abstract}

Objective: The study was conducted to assess comprehensive knowledge, attitude and practice level of the community towards malaria and associated factors in Areka town, Southern Ethiopia.

Methods: Community-based cross sectional study was conducted in Areka town from 15-25 January 2015. Data obtained from heads of households or their spouse or a family member aged 18 years or above using semistructured questionnaire. Knowledge, attitude and practice levels were measured by using likert scales. Above median scores were used to determine good knowledge, positive attitude and good practice. Binary logistic regression analyses were performed to identify associated factors.

Result: Data collected from 405 households. Among the total of 405 respondents participated in the study, 204 $(50.4 \%)$ had good knowledge while $201(49.6 \%)$ had poor knowledge on malaria. Those study participants with educational level of College and above were 6 times more likely to have good knowledge of malaria as compared to their illiterate counterparts $($ AOR $(95 \%$ C.I $)=6.377(2.525,16.109))(p<0.001)$. Of the respondents, $223(55.1 \%)$ had positive attitude while $182(44.9 \%)$ had negative attitude towards malaria. Those who had good knowledge of malaria were 3 times more likely to have positive attitude towards malaria when compared to the ones having poor knowledge (AOR (95\% C.I=3.069 (1.926, 4.893)) $(p<0.001)$. Regarding practice, $274(67.7 \%)$ of the study participants had good practice while $131(32.3 \%)$ had poor practice in terms of malaria treatment, prevention and control. Those having positive attitude towards malaria were about 5 times more likely to practice good when compared to the one's having negative attitude $(\operatorname{AOR}(95 \% \mathrm{C} . \mathrm{I})=4.771(2.885,7.887))(p<0.001)$.

Conclusion: Comprehensive level of knowledge, attitude and practice towards malaria were more or less comparable with most other studies. Positive attitude towards malaria was enhanced by knowledge of malaria, and in turn good practice on malaria was enhanced by positive attitude.

Keywords: Knowledge; Attitude; Practice; Malaria

\begin{abstract}
Abbreviations
ACT: Artemisinin-based Combination Therapy; OR: Adjusted Odds Ratio; C.I: Confidence Interval; IQR: Inter Quartile Range; IRS: Indoor Residual Spray; ITN: Insecticide-Treated Net; KAP: Knowledge, Attitude and Practice; KM: Kilo Meter; LLIN: Long Lasting Insecticide Treated Net; NSP: National Strategic Plan for Malaria Control and Prevention; $P$. falciparum: Plasmodium falciparum; $P$. vivax: Plasmodium vivax, SPSS: Statistical Package for Social Sciences; US\$: United States Dollar; WHO: World Health Organization.
\end{abstract}

\section{Introduction}

Malaria is an infectious vector borne disease caused by four common species of the protozoan parasites of the genus Plasmodium;
Plasmodium falciparum, Plasmodium vivax, Plasmodium ovalae and Plasmodium malariae. P. falciparum is the most deadly form and predominantly occurring followed by $P$. vivax. Malaria is one of the major causes of morbidity and mortality in tropical and subtropical countries. Malaria parasites are transmitted to humans by the bite of infected female anopheles mosquitoes that inoculates spindle shaped sporozoites into the human bloodstream. Malaria is a very common cause of fever in tropical countries. It is acutely manifested by nonspecific symptoms such as lack of a sense of well-being, headache, fatigue, and abdominal discomfort, muscle aches followed by classic malarial paroxysms of spiking fever, chills, and rigors [1,2].

Globally, an estimated 3.3 billion people are at risk of being infected with malaria and developing disease, 1.2 billion of which being at high risk. According to the latest estimates, globally, 198 million (124-283 million) cases and 58,4000 deaths $(36,7000-75,5000)$ of malaria occurred in 2013 alone. The burden is heaviest in the WHO African 
Region, accounting an estimated $90 \%$ of all malaria cases and deaths [3]. It is not only cause of suffering and death, but also the cause of many socioeconomic problems. For instance, malaria costs the African nations more than US\$12 billion annually [4].

Despite substantial progress in the prevention and control for the last decades, malaria remains to be an important public health problem in Ethiopia. Over the past couple of years, the disease has been consistently reported as the first leading cause of outpatient visits, hospitalization and death in health facilities across the country [5]. According to the Federal Ministry of Health, in 2011/2012, malaria was the leading cause of outpatient visits, accounting for $17 \%$ of all outpatient visits, and $8 \%$ of health facility admissions among all age groups. It was one of the top ten causes of inpatient deaths among children aged less than five years and in older individuals. In $2012 / 2013$, there were 57,503 public sector malaria hospitalizations, 4,984,266 malaria outpatient cases, and 2,942,031 laboratory confirmed $P$. falciparum and 1,258,131 $P$. vivax outpatient malaria cases [6]. According to records from the Federal Ministry of Health, $75 \%$ of the country is malarious with about $68 \%$ of the total population living in areas at risk of malaria. That means, more than 50 million people are at risk of malaria, and an estimated 4-5 million people are affected by malaria annually $[7,8]$. According to recent malaria status report, 2-3.5 million total malaria cases and 100-450 malaria deaths occurred from 2013 to 2014 in the country [9].

Malaria is an entirely preventable and treatable disease, provided the currently recommended interventions are properly implemented [3]. Prevention and control activities of malaria in Ethiopia are implemented as guided by the National Strategic Plan (NSP) with four major intervention strategies-early diagnosis and prompt treatment with the highly efficacious artemisinin-based combination therapies (ACTs), selective vector control that involves use of insecticide-treated mosquito nets (ITNs), indoor residual spraying (IRS) and environmental management to ultimately reduce the burden of malaria to a level where it is no longer a public health problem $[8,10]$. The feasibility of appropriately preventing incidence of the disease is largely based on the available data at each level [8].

Among the strategic objectives of the national malaria prevention and control of Ethiopia, NSP 2014-2020, is that by 2020 all households living in malaria endemic areas will have the knowledge, attitude and practice towards malaria prevention and control [6]. For successful malaria intervention, community's knowledge level is crucial and views are great in guiding practices to ensure appropriate treatment, prevention and control measures [11]. Understanding knowledge level, perception towards and practical behaviors of individuals and communities is crucial for designing appropriate intervention strategies.

Different studies have tried to assess communities knowledge, perception and behaviors towards malaria among communities in different parts of the country. These studies have demonstrated communities' level of understandings and revealed some misconceptions related to signs and symptoms, mode of transmission, treatment or prevention of malaria. For instance, in a study from Tigray region, Ethiopia, mosquito as a cause of malaria was recognized by nearly half of the respondents (48.8\%) [12]. In another study conducted among households in urban areas of Assosa zone, western Ethiopia, about $48 \%$ of study participants were aware that malaria can be transmitted by mosquito bites, and remarkable proportion of respondents had misconceptions regarding modes of malaria transmission [13]. In a study conducted in Amahara National Regional
State, Ethiopia, only $32.3 \%$ of study participants knew that Anopheles mosquitoes are responsible for transmission of malaria, while only $61.29 \%$ of respondents believed that malaria can be prevented by using bed nets, and only $69 \%$ of respondents had positive attitude towards modern health care utilization for malaria treatment. It was also observed that misconceptions about causes and transmissions of malaria were very common, where exposure to cold weather, hunger, and drinking dirty water were mentioned as causes of malaria [14]. Misconceptions regarding cause of malaria were also observed in another study conducted in Jimma town, southwest Ethiopia, where unhygienic condition and cold weather were mentioned as causes of malaria by $13.1 \%$ and $1.4 \%$ of respondents, respectively [15]. As to practical behaviors related to malaria, it was reported from Shewa Robit town, northeastern Ethiopia, that only $57 \%$ of respondents have slept under ITNs every night, while $87.7 \%$ and $59.5 \%$ of respondents ever practiced use of mosquito nets and housespray with insecticide, respectively [16]. In the study from Amahara National Regional State, Ethiopia, it was only $26.4 \%$ of the study participants that used ITN as malaria prevention and control method, and $47 \%$ of the total study participants were regarded as having good practice towards malaria prevention and control activities, while the remaining 53\% having had poor practice [14]. On the other hand, in a study reported from a rural community of Ethiopia, it was reported that $6.8 \%$ of the study participants used both modern and traditional medicine, while $1.3 \%$ used only traditional medicine for treatment of malaria [17]. In line with this, it was reported by another study from Ethiopia, that a sizable fraction of respondents had misconceptions and undesirable health seeking behavior [18].

However, almost all of these and other studies focused on specific aspects related to malaria, such as signs and symptoms, mode of transmission, ITN utilization, or treatment. None of them came up with comprehensive knowledge, attitude and practical behaviors of individuals or communities towards malaria. Moreover, knowledge of malaria, perception and practice of the community towards malaria is not investigated in the study area. With these gaps in mind, this study was undertaken to assess comprehensive knowledge, attitude and practice level of the community with regard to cause, seriousness and threat, treatment, prevention and control of malaria in the study area. Moreover, it assesses the association between socio-demographic factors and KAP towards malaria. The findings from the study have significant contribution in prevention and control of malaria. It is hoped to be providing policy makers, program planners, the local woreda health office, or in particular disease prevention and control department as well as other concerned bodies with scientific and updated information relevant for designing appropriate intervention strategies and to ensure appropriate prevention and control measures.

\section{Materials and Methods}

\section{Study area and period}

The study was conducted in Areka town, located in Wolaita Zone Southern Ethiopia, at $298 \mathrm{~km}$ from Addis Ababa to the southern part of the country. It is situated at altitude of 501 to 25000 meters above sea level. The climatic condition of the town is temperate and cold with the annual rainfall of from 1201 to $1600 \mathrm{~mm}$. High Rainfall is registered from June to August with the mean annual rainfall of $1400 \mathrm{~mm}$ and the mean annual temperature ranging from 17.6 to $22.50^{\circ} \mathrm{C}$. The area is known to be one of the malarious areas in Wolaita zone. According to the Central Statistics Agency the total population of the town is 
estimated to be about 50,000 with a male to female ratio of $1: 1$ and a total of 9232 households. According to routine reports from local health facilities, malaria is among the ten top diseases in the outpatient departments across all health facilities in the town, and is one of the leading causes of morbidity and mortality in the area. According to the annual report of the local health department, an estimated $20-35 \%$ of the population is affected by malaria annually [19]. Currently, there is one hospital, one health center and 7 private clinics in the town. The study was conducted from 15 to 25 January 2015.

\section{Study design}

Community-based cross-sectional study design was used.

\section{Inclusive criteria}

Head of household or their spouse or any family member aged 18 years or above who have stayed in the study area as permanent resident for at least 6 months were eligible for the interview.

\section{Sample size determination}

The number of households to be included in the sample was determined by single population proportion formula, $\mathrm{Za} / 2) 2(\mathrm{p})(1-$ $\mathrm{p}) / \mathrm{d} 2$. The proportion (p) for the sample size determination was used from a study conducted in Amahara national regional state of Ethiopia, in which $47 \%$ of respondents had good practice on malaria [14]. This proportion was used for our sample size calculation as it gave relatively larger sample. Assuming 95\% confidence level, 5\% margin of error, using correction formula for source population less than 10,000 (the total number of households in the town is 9232), and finally considering $10 \%$ contingency for possible non- response rate, the final sample size was 405 .

\section{Sampling technique and procedure}

Systematic sampling technique was used to select 405 households from among the total of 9232 households in the town that were given numbers from 1 to 9232 . The sampling interval for selection of the households was calculated to be 23 . The second household was randomly selected by lottery method from among the first 23 households as the first random start. Then, every 23rd household was included until 405 households were achieved.

\section{Measurement}

To measure knowledge, a total of six multiple choice questions were used each providing series of 'right' and 'wrong' response options related to cause, transmission, signs and symptoms, treatment, prevention and control of malaria. Each of these questions was scored 1 for right answer and 0 for wrong answer. An individual's overall knowledge score was calculated by adding up the scores for each respondent across all the questions, and median knowledge score was computed across all the study participants. A study participant's knowledge level was determined by comparing his/her knowledge score against the median knowledge score. A study participant was claimed to have good knowledge/is knowledgeable if his/her knowledge score is equal to or more than the median knowledge score, have poor knowledge otherwise.

Attitude was measured using a combination of seven positive and seven negative statements that are related to susceptibility, seriousness and threat or consequences, treatment, prevention and control options of malaria. For each question item, 5-point likert scale ranging from strongly disagree (score 1), disagree (score 2), undecided (score 3), agree (score 4), to strongly agree (score 5) for positive statement and the reverse scale, strongly disagree (score 5), disagree (score 4), undecided (score 3), agree (score 2) to strongly agree (score 1) for negative statement was used. An individual's overall attitude score was determined by adding up the scores across all the fourteen questions and median attitude score was computed across all the study participants.

To gauge an individual's attitude, the individual's attitude score was compared against the median attitude score. An individual was said to have positive attitude if his/her attitude score is equal to or more than the median attitude score have negative attitude otherwise.

Practice was measured using a total of eight good practice statements related to treatment, prevention and control of malaria. For each question item, 3-point likert type scale ranging from never (score 0 ), sometimes (score 1), always (score 2) was used. An individual's overall practice score was calculated by adding up the scores across all the eight questions and median practice score was computed across all the study participants. An individual was claimed as having good practice when his/her overall practice score is equal to or more than the median practice score.

\section{Data collection}

Data was collected using interviewer-administered questionnaire which consisted of six questions assessing knowledge, fourteen questions assessing attitude and eight questions assessing practice. The questionnaire was first developed in English, and was translated to Amharic language. The data was collected by five clinical nurses using the Amharic version of the questionnaire.

\section{Data processing and analysis}

Data entry, cleaning, categorizing, coding and analysis were performed using SPSS 20 for windows. Respondents' age was categorized based on age quartiles and considering other literatures for comparison purpose. With the first quartile of 20 years, the second quartile (median) of 25 years and the third quartile 30 years, and considering the case of other literatures, age of respondents was categorized in to three as below 25 years (18-25 years), 26-35 years and above 35 years (36-70 years). Individual knowledge, attitude and practice scores were computed median scores computed for each, and one's knowledge, attitude and practice level was determined according to the pre-defined criterion. Binary logistic regression analyses were performed to examine associations.

\section{Results}

\section{Socio-demographic characteristics}

Data collected from 405 households. Among a total of 405 respondents participated in the study, 203 (50.1\%) were males and 202 (49.9\%) females. The median (IQR) age of respondents was 25 years. About half of the respondents, 205 (50.6\%) were in the age range of 18-25 years, followed by 26-35 years accounting 147 (36.3\%). Majority, 385 (95.1\%) of the study participants were Wolaita in their ethnicity. With regard to educational status, 193 (47.7\%) of the study participants had attended secondary school while $41(10.1 \%)$ were illiterate (Table $1)$. 
Citation: Kebede DL, Hibstu DT, Birhanu BE, Bekele FB (2017) Knowledge, Attitude and Practice Towards Malaria and Associated Factors in Areka Town, Southern Ethiopia: Community-Based Cross-Sectional Study. J Trop Dis 5: 240. doi:10.4172/2329-891X.1000240

Page 4 of 11

\begin{tabular}{|l|l|l|}
\hline \multicolumn{2}{|l|}{ Variable } & \multicolumn{2}{l|}{ Frequency } & Percent (\%) \\
\hline Sex & 203 & 50.1 \\
\hline Male & 202 & 49.9 \\
\hline Female & \multicolumn{2}{l|}{} \\
\hline Age category (years) & 205 & 50.6 \\
\hline $18-25$ & 147 & 36.3 \\
\hline $26-35$ & 53 & 13.1 \\
\hline $36-70$ & \multicolumn{2}{|l|}{} \\
\hline Ethnicity & 385 & 95.1 \\
\hline Wolaita & 20 & 4.9 \\
\hline Other & & \\
\hline Religion & 144 & 35.6 \\
\hline Orthodox & 16 & 4.4 \\
\hline Muslim & 205 & 50.6 \\
\hline Protestant & 22 & 5.4 \\
\hline Catholic & 16 & 4 \\
\hline Other & & \\
\hline Educaton & & \\
\hline
\end{tabular}

\section{Knowledge of malaria}

Respondents answered series of multiple choice questions used to assess knowledge related to cause, transmission, signs and symptoms, treatment, prevention and control of malaria. Majority, 379 (93.6\%) of the respondents correctly identified fever, headache, chills, sweating and malaise to be the most common signs and symptoms of malaria. Of the total respondents, 304 (75.1\%) of had correct understanding of mode of transmission of malaria while $101(24.9 \%)$ did not correctly identify that malaria is transmitted by bite of mosquitoes. On the other hand, $345(85.2 \%)$ of the respondents correctly mentioned use of antimalarial drugs for treating malaria, whereas 363 (89.6\%) correctly mentioned use of insecticide treated mosquito nets and draining stagnant water or moist areas as means of malaria prevention.

Overall knowledge score was calculated for each participant. The median (IQR) knowledge score across all the study participants was 14 (7). Knowledge level was determined by comparing one's knowledge score against the median knowledge score. Knowledge score of 14 and above is determined to be good knowledge whereas that below 14 is labeled as poor knowledge. Accordingly, 204 (50.4\%) of the study participants had good knowledge while 201 (49.6\%) had poor knowledge on malaria.

Multiple logistic regression analysis was performed to identify factors associated with one's knowledge of malaria. Educational level was found to have significant association with individual's knowledge of malaria. In this regard, study participants with educational level of College and above were 6 times more likely to have good knowledge of malaria as compared to their illiterate counterparts (AOR $(95 \%$ C.I $)=6.377(2.525,16.109))(\mathrm{p}<0.001)($ Table 2$)$.

\begin{tabular}{|l|l|l|}
\hline Illiterate & 41 & 10.1 \\
\hline $1-8$ & 91 & 22.5 \\
\hline $9-12$ & 193 & 47.7 \\
\hline College and above & 80 & 19.8 \\
\hline Marital status & \multicolumn{2}{|l|}{} \\
\hline Married & 193 & 47.6 \\
\hline Single & 200 & 49.4 \\
\hline Widowed & 7 & 1.7 \\
\hline Divorced & 5 & 1.2 \\
\hline Occupation & & \\
\hline Government employee & 100 & 24.7 \\
\hline Private employee & 17 & 4.2 \\
\hline Merchant & 103 & 25.4 \\
\hline Farmer & 13 & 3.2 \\
\hline Daily laborer & 17 & 4.2 \\
\hline Housewife & 51 & 12.6 \\
\hline Student & 103 & 25.4 \\
\hline Other & 1 & \\
\hline & & \\
\hline
\end{tabular}

\begin{tabular}{|l|l|l|}
\hline Variable & AOR (95\% C.I) & p-value \\
\hline Sex & 1.000 & 0.217 \\
Female & $0.754(0.482,1.180)$ & \\
\hline Age category (years) & 1.000 & 0.295 \\
$18-25$ & $1.306(0.793,2.152)$ & 0.203 \\
$26-35$ & $1.641(0.766,3.518)$ & \\
$36-70$ & & \\
\hline Religion & 1.000 & 0.547 \\
Orthodox & $0.721(0.249,2.092)$ & 0.657 \\
Muslim & $0.896(0.551,1.456)$ & 0.184 \\
Protestant & $0.499(0.179,1.391)$ & 0.426 \\
Catholic & $0.605(0.176,2.084)$ & \\
Other & & \\
\hline Educational level & 1.000 & 0.150 \\
Illiterate & $1.791(0.810,3.960)$ & 0.136 \\
Grade 1-8 & $0.552(0.253,1.205)$ & $0.000^{*}$ \\
Grade 9-12 & $6.377(2.525,16.109)$ & \\
College and above & & \\
\hline *Statistically significant at $\alpha=0.05$ & \\
\hline
\end{tabular}

Table 1: Socio-demographic characteristics of the study participants,

Table 2: Multiple logistic regression analysis of knowledge level (good) and socio-demographic variables, Areka town, Jan 2015. 
Citation: Kebede DL, Hibstu DT, Birhanu BE, Bekele FB (2017) Knowledge, Attitude and Practice Towards Malaria and Associated Factors in Areka Town, Southern Ethiopia: Community-Based Cross-Sectional Study. J Trop Dis 5: 240. doi:10.4172/2329-891X.1000240

Page 5 of 11

\section{Attitude towards malaria}

Respondents answered a combination of 7 positive and 7 negative statements that are related to susceptibility, seriousness and threat or consequences, treatment, prevention and control of malaria. Of respondents, $337(83.2 \%)$ agreed to seriousness and threat posed by malaria. The larger proportion, $355(87.7 \%)$ agreed on avoiding mosquito bite as the best way of malaria prevention. On the other hand, $356(87.9 \%)$ of the study participants agreed to sleeping under a mosquito net during the night as a method of preventing oneself from getting malaria. The majority, $372(91.8 \%)$ of respondents agreed to (had positive attitude towards) modern healthcare to treatment of malaria.
Misconceptions regarding malaria cause, treatment, prevention and control were also reflected from the responses to negative attitude questions. For instance, $63(15.6 \%)$ of the study participants had misconception regarding cause and prevention of malaria as they agreed or undecided to the statement that one can prevent him/herself from malaria by avoiding sinful nature or guilty behavior.

About one in five, 78 (19.26\%), of the study participants had misconception regarding treatment of malaria as they were undecided or believed on traditional medicine as treatment option of malaria. The study participants' responses to series of positive statements and negative statements are summarized under Tables 3 and 4, respectively.

\begin{tabular}{|c|c|c|c|c|c|}
\hline \multirow[t]{2}{*}{ Positive statement } & $\begin{array}{l}\text { Strongly } \\
\text { disagree (1) }\end{array}$ & $\begin{array}{l}\text { Disagree } \\
\text { (2) }\end{array}$ & $\begin{array}{l}\text { Undecided } \\
\text { (3) }\end{array}$ & $\begin{array}{l}\text { Agree } \\
(4)\end{array}$ & $\begin{array}{l}\text { Strongly } \\
\text { agree (5) }\end{array}$ \\
\hline & $\begin{array}{l}\text { Frequency } \\
\text { (\%) }\end{array}$ & $\begin{array}{l}\text { Frequency } \\
\text { (\%) }\end{array}$ & $\begin{array}{l}\text { Frequency } \\
\text { (\%) }\end{array}$ & $\begin{array}{l}\text { Frequency } \\
(\%)\end{array}$ & $\begin{array}{l}\text { Frequency } \\
\text { (\%) }\end{array}$ \\
\hline $\begin{array}{l}\text { 1. I am sure anyone can get } \\
\text { malaria }\end{array}$ & $24(5.9 \%)$ & $39(9.6 \%)$ & $7(1.7 \%)$ & $180(44.4 \%)$ & 155 (38.3\%) \\
\hline $\begin{array}{l}\text { 2. I think malaria is a serious } \\
\text { and life-threatening (fatal) disease }\end{array}$ & $17(4.2 \%)$ & $35(8.6 \%)$ & $16(4.0 \%)$ & $179(44.2 \%)$ & $158(39.0 \%)$ \\
\hline $\begin{array}{l}\text { 3. I think the best way to prevent myself getting } \\
\text { malaria is to avoid getting mosquito } \\
\text { bites }\end{array}$ & $22(5.4 \%)$ & $20(4.9 \%)$ & $8(2.0 \%)$ & $197(48.6 \%)$ & $158(39.0 \%)$ \\
\hline $\begin{array}{l}4 . I \text { believe sleeping under a } \\
\text { mosquito net during the night is one way to } \\
\text { prevent myself } \\
\text { getting malaria }\end{array}$ & $21(5.2 \%)$ & $21(5.2 \%)$ & $7(1.7 \%)$ & $189(46.7 \%)$ & $167(41.2 \%)$ \\
\hline $\begin{array}{l}5 . \text { I think it is risky when malaria medicine is not } \\
\text { taken } \\
\text { properly and completely }\end{array}$ & $21(5.2 \%)$ & $29(7.2 \%)$ & $7(1.7 \%)$ & $228(56.3 \%)$ & $120(29.6 \%)$ \\
\hline $\begin{array}{l}\text { 6. I think I need to visit health center/clinic when I } \\
\text { am } \\
\text { suspected of malaria }\end{array}$ & $12(3.0 \%)$ & $12(3.0 \%)$ & $9(2.2 \%)$ & $219(54.1 \%)$ & $153(37.8 \%)$ \\
\hline $\begin{array}{l}\text { 7. I think one can prevent him/herself from getting } \\
\text { malaria }\end{array}$ & $13(3.2 \%)$ & $31(7.7 \%)$ & $8(2.0 \%)$ & $218(53.8 \%)$ & $135(33.3 \%)$ \\
\hline
\end{tabular}

Table 3: The study participants' response towards positive attitude questions, Areka town, Jan 2015.

\begin{tabular}{|c|c|c|c|c|c|}
\hline \multirow[t]{2}{*}{ Negative statement } & $\begin{array}{l}\text { Strongly } \\
\text { disagree (5) }\end{array}$ & Disagree (4) & $\begin{array}{l}\text { Undecided } \\
\text { (3) }\end{array}$ & $\begin{array}{l}\text { Agree } \\
(2)\end{array}$ & $\begin{array}{l}\text { Strongly } \\
\text { agree (1) }\end{array}$ \\
\hline & $\begin{array}{l}\text { Frequency } \\
(\%)\end{array}$ & $\begin{array}{l}\text { Frequency } \\
(\%)\end{array}$ & $\begin{array}{l}\text { Frequency } \\
(\%)\end{array}$ & $\begin{array}{l}\text { Frequency } \\
(\%)\end{array}$ & $\begin{array}{l}\text { Frequency } \\
(\%)\end{array}$ \\
\hline $\begin{array}{l}\text { 1. Malaria can be transmitted from person to } \\
\text { person just like } \\
\text { common cold }\end{array}$ & $232(57.3 \%)$ & $124(30.6 \%)$ & $18(4.4 \%)$ & $19(4.7 \%)$ & $12(3.0 \%)$ \\
\hline $\begin{array}{l}\text { 2. I am sure I can treat myself } \\
\text { if I get malaria }\end{array}$ & $196(48.4 \%)$ & $145(35.8 \%)$ & $19(4.7 \%)$ & $27(6.7 \%)$ & $18(4.4 \%)$ \\
\hline $\begin{array}{l}\text { 3. I believe that traditional medicines play big } \\
\text { roles in }\end{array}$ & $200(49.4 \%)$ & $127(31.4 \%)$ & $37(9.1 \%)$ & $34(8.4 \%)$ & $7(1.7 \%)$ \\
\hline
\end{tabular}


Citation: Kebede DL, Hibstu DT, Birhanu BE, Bekele FB (2017) Knowledge, Attitude and Practice Towards Malaria and Associated Factors in Areka Town, Southern Ethiopia: Community-Based Cross-Sectional Study. J Trop Dis 5: 240. doi:10.4172/2329-891X.1000240

Page 6 of 11

\begin{tabular}{|l|l|l|l|l|l|}
\hline curing malaria & & & & \\
\hline $\begin{array}{l}4 . \text { In my opinion, it's only } \\
\text { children and pregnant women at risk of malaria }\end{array}$ & $211(52.1 \%)$ & $128(31.6 \%)$ & $21(5.2 \%)$ & $34(8.4 \%)$ & $11(2.7 \%)$ \\
\hline $\begin{array}{l}\text { 5. I think that one can } \\
\text { recover spontaneously from malaria without any } \\
\text { treatment }\end{array}$ & $215(53.1 \%)$ & $139(34.3 \%)$ & $15(3.7 \%)$ & $22(5.4 \%)$ & $14(3.5 \%)$ \\
\hline $\begin{array}{l}\text { 6. If someone has got malaria, people should } \\
\text { avoid having } \\
\text { close contact with him/her }\end{array}$ & $214(52.8 \%)$ & $122(30.1 \%)$ & $17(4.2 \%)$ & $37(9.1 \%)$ & $15(3.7 \%)$ \\
\hline $\begin{array}{l}\text { 7. I believe one can prevent him/herself from } \\
\text { malaria by avoiding sinful nature or guilty } \\
\text { behavior }\end{array}$ & $240(59.3 \%)$ & $102(25.2 \%)$ & $24(5.9 \%)$ & $24(5.9 \%)$ & $15(3.7 \%)$ \\
\hline
\end{tabular}

Table 4: The study participants' response towards negative attitude questions, Areka town, Jan 2015.

Overall attitude was gauged by measuring one's level of agreement using 5-point likert scale ranging from strongly disagree to strongly agree to each of the above statements. A study participant's overall attitude score was calculated. The median (IQR) attitude score across all the study participants was 59 (11).

Attitude level was determined by comparing one's attitude score against the median attitude score. Attitude score of 59 and above is determined to be positive attitude whereas that below 59 is labeled as negative attitude. Accordingly, 223 (55.1\%) of the study participants had positive attitude while $182(44.9 \%)$ had negative attitude towards malaria in terms of its susceptibility, seriousness or threat, treatment, prevention and control (Figure 1).

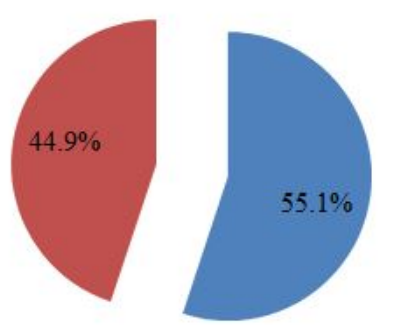

Positive attitude

Negative attitude

Figure 1: Distribution of attitude level towards malaria amongst study participants, Areka town, January 2015.

From multiple logistic regression analysis, educational level of grade 9-12 was found to have negative association with attitude towards malaria. Those with educational level of grade 9-12 were $65 \%$ less likely to have positive attitude on malaria when compared to their illiterate counterparts $($ AOR $(95 \%$ C.I $)=0.354(0.157,0.798))(p=0.012)$.

A study participant's attitude was found to be significantly associated with his/her knowledge of malaria.

Those who had good knowledge of malaria were 3 times more likely to have positive attitude towards malaria when compared to the ones having poor knowledge (AOR (95\% C.I) $=3.069 \quad(1.926,4.893)$ ) $(\mathrm{p}<0.001)$ (Table 5).

\begin{tabular}{|l|l|l|}
\hline Variable & AOR $(95 \%$ C.I) & P-value \\
\hline Sex & 1.000 & 0.770 \\
Female & $1.069(0.682,1.677)$ & \\
\hline Age category (years) & 1.000 & \\
\hline $18-25$ & $0.990(0.592,1.658)$ & 0.469 \\
$26-35$ & $0.753(0.350,1.622)$ & \\
$36-70$ & & \\
\hline Religion & 1.000 & 0.700 \\
Orthodox & $1.242(0.412,3.738)$ & 0.773 \\
Muslim & $0.931(0.570,1.519)$ & 0.610 \\
Protestant & $0.767(0.277,2.123)$ & $0.008^{*}$ \\
Catholic & $0.174(0.048,0.631)$ & \\
Other & & \\
\hline Educational level & 1.000 & 0.496 \\
Illiterate & $1.346(0.573,3.160)$ & $0.012^{*}$ \\
Grade 1-8 & $0.354(0.157,0.798)$ & 0.638 \\
Grade 9-12 & $1.243(0.502,3.078)$ & \\
College and above & & \\
\hline Knowledge level & 1.000 & \\
Poor & $3.069(1.926,4.893)$ & \\
Good & & \\
\hline *Statistically significant at & $\alpha=0.05$ & \\
\hline
\end{tabular}

Table 5: Multiple logistic regression analysis of attitude level (positive) and socio- demographic variables, Areka town, January 2015.

\section{Practice towards malaria}

Respondents answered eight good practice questions related to treatment, prevention and control of malaria. Practice was gauged by measuring one's frequency of practicing these aspects. Majority of the respondents reported that they were often performing the good practices of malaria prevention and control. More than $60 \%$ of the study participants responded that they always seek medical care when 
Citation: Kebede DL, Hibstu DT, Birhanu BE, Bekele FB (2017) Knowledge, Attitude and Practice Towards Malaria and Associated Factors in Areka Town, Southern Ethiopia: Community-Based Cross-Sectional Study. J Trop Dis 5: 240. doi:10.4172/2329-891X.1000240

Page 7 of 11

they or their family member gets sick. About three fourth, $305(75.3 \%)$ of the study participants reported that they always sleep in an insecticide treated mosquito nets. Of the respondents, $192(47.4 \%)$ reported that they always drain stagnant water or moist areas around their home (Table 6).

\begin{tabular}{|l|l|l|l|}
\hline Good practice questions & Never (0) & Sometimes (1) & Always (2) \\
\cline { 2 - 4 } & Frequency (\%) & Frequency (\%) & Frequency (\%) \\
\hline $\begin{array}{l}\text { 1. How often do you visit the health center/clinic when } \\
\text { you fall sick? }\end{array}$ & $18(4.4 \%)$ & $121(29.9 \%)$ & $266(65.7 \%)$ \\
\hline $\begin{array}{l}\text { 2. How do you describe your habit of visiting health } \\
\text { center/clinic when any other family member falls sick? }\end{array}$ & $21(5.2 \%)$ & $109(26.9 \%)$ & $275(67.9 \%)$ \\
\hline $\begin{array}{l}\text { 3. How often do you sleep in an insecticide treated } \\
\text { mosquito net (ITN)? }\end{array}$ & $23(5.7 \%)$ & $77(19.0 \%)$ & $305(75.3 \%)$ \\
\hline \begin{tabular}{l} 
4. How often do other family members sleep in mosquito nets? \\
\hline $\begin{array}{l}\text { 5. How do you describe your habit of checking for } \\
\text { holes/repair mosquito nets? }\end{array}$
\end{tabular} & $22(5.4 \%)$ & $92(22.7 \%)$ & $291(71.9 \%)$ \\
\hline $\begin{array}{l}\text { 6. How often do you use anti-mosquito spray (IRS) in } \\
\text { your house? }\end{array}$ & $27(6.7 \%)$ & $177(43.7 \%)$ & $199(49.15)$ \\
\hline $\begin{array}{l}\text { 7. How do you describe your habit of trimming bushes } \\
\text { around your home? }\end{array}$ & $16(4.0 \%)$ & $285(70.4 \%)$ & $93(23.0 \%)$ \\
\hline $\begin{array}{l}\text { 8. How often do you drain stagnant water/moist areas } \\
\text { around your home? }\end{array}$ & $30(7.4 \%)$ & $203(50.1 \%)$ & $186(45.9 \%)$ \\
\hline
\end{tabular}

Table 6: Participants response to good practice questions related to treatment, prevention and control of malaria, Areka town, January 2015.

A study participant's overall practice score was calculated, and the median (IQR) practice score across all the study participants was 12 (3). Practice level was determined by comparing one's practice score against the median practice score. Practice score of 12 and above is determined to be good practice whereas that below 12 is labeled as poor practice. Accordingly, 274 (67.7\%) of the study participants had good practice while 131 (32.3\%) had poor practice in terms of malaria treatment, prevention and control (Figure 2).

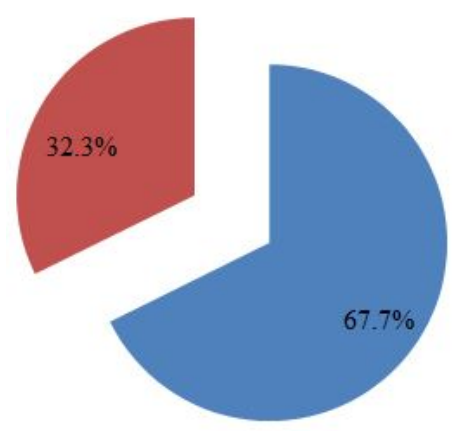

- Good practice

- Poor practice

Figure 2: Distribution of practice level on malaria amongst respondents; Areka town, January 2015.

From multiple logistic regression analysis, a study participant belonging to Catholic religion was 3.7 times more likely to have good practice on malaria when compared the one from Orthodox religion $(\operatorname{AOR}(95 \%$ C.I $)=3.705(1.062,12.921))(p=0.04)$. Practice on malaria was found to be significantly associated with one's attitude. Those having positive attitude regarding susceptibility, seriousness and threat or consequences, treatment, prevention and control of malaria were about 5 times more likely to practice good when compared to the one's having negative attitude (AOR (95\% C.I $)=4.771 \quad(2.885,7.887)$ ) $(\mathrm{p}<0.001)$. Respondents' sex, age category, educational level, and knowledge of malaria were found to have no association with practice (Table 7).

\begin{tabular}{|l|l|l|}
\hline Variable & AOR $(95 \%$ C.I $)$ & p-value \\
\hline Sex & 1.000 & 0.339 \\
Female & $1.261(0.784,2.027)$ & \\
\hline Age category (years) & 1.000 & 0.304 \\
$18-25$ & $0.748(0.431,1.300)$ & 0.292 \\
$26-35$ & $0.635(0.273,1.478)$ & \\
$36-70$ & 1.000 & \\
\hline Religion & $2.227(0.612,8.108)$ & 0.328 \\
Orthodox & $1.292(0.773,2.157)$ & $0.040^{*}$ \\
Muslim & $3.705(1.062,12.921)$ & 0.359 \\
Protestant & $0.584(0.185,1.841)$ & \\
Catholic & & \\
Other & & \\
\hline
\end{tabular}




\begin{tabular}{|l|l|l|}
\hline Educational level & 1.000 & 0.772 \\
Illiterate & $0.868(0.332,2.267)$ & 0.123 \\
Grade 1-8 & $0.485(0.193,1.216)$ & 0.921 \\
Grade 9-12 & $1.053(0.379,2.928)$ & \\
College and above & & \\
\hline $\begin{array}{l}\text { Knowledge level } \\
\text { Poor }\end{array}$ & 1.000 & 0.278 \\
Good & $1.334(0.793,2.246)$ & \\
\hline Attitude level & 1.000 & $0.000^{*}$ \\
Negative & $4.771(2.885,7.887)$ & \\
Positive & & \\
\hline *Statistically significant at $\mathrm{\alpha}=0.05$ & \\
\hline
\end{tabular}

Table 7: Multiple logistic regression analysis of practice level (good) and socio-demographic variables, Areka town, January 2015.

\section{Discussion}

This study has investigated the comprehensive knowledge of malaria, the perception, and practical behaviors of the community with regard to treatment seeking, prevention and control of malaria in the study area. It provides scientific information that could be of great importance for designing evidence-based intervention strategies and guiding appropriate prevention and control measures of malaria in the study area.

In this regard, the majority, 379 (93.6\%) of the study participants correctly identified fever, headache, chills, sweating and malaise to be the most common signs and symptoms of malaria. This finding is higher when compared to the finding from Nigeria, where $65.2 \%$ of respondents mentioned fever with shivering as the common symptoms of malaria [20] and that of Botswana, where the proportion of respondents that showed some basic knowledge on signs and symptoms of malaria were $88.7 \%$ [21], and the study in Pawe District, North West Ethiopia, in which about $84.7 \%$ and $83 \%$ of the respondents stated fever and headache respectively as the most common primary symptoms associated with malaria [1]. The current finding, is, however, consistent with the study from Shewa Robit town, Northwestern Ethiopia, where fever and chills were mentioned as symptoms of the disease by $94.4 \%$ and $93.3 \%$ of the respondents, respectively [16]. It was observed that about three forth $(75.1 \%)$ of respondents had correct understanding of mode of transmission of malaria. This finding is comparable with the report from a study in Nigeria in which $74.3 \%$ of the study participants has mentioned mosquito bite as mode of malaria transmission [20], and Iran, in which $77.8 \%$ of respondents believed that malaria is transmitted through the bite of mosquitoes [22], but slightly lower than the report from Tanzania, where $80.2 \%$ of the study participants knew that the disease is transmitted by mosquitoes [23], and Botswana where malaria transmission as the result of mosquito bite was mentioned by $93 \%$ of the interviewees [21]. However, it is higher when compared with reports from different parts of Ethiopia, where the proportion of respondents that have linked malaria transmission with mosquito bite was about $48 \%[16,13]$. On the other hand, $363(89.6 \%)$ of respondents participated in this study correctly mentioned use of insecticide treated mosquito nets and draining stagnant water or moist areas as means of malaria prevention. The finding is higher when compared with the report from a study in Iran, in which $60.8 \%$ of respondents mentioned the use of LLINs as a preventive measure against malaria [22], and that of Nigeria, where $64.0 \%$ of respondent had knowledge of insecticide treated bed net (ITNs) as protective measures against malaria [20]. It is also higher than the report from Amahara National Regional State, Ethiopia, where $61.29 \%$ of respondents reported that malaria is preventable by using bed nets [14], but slightly lower when compared with another Ethiopian study, in which $97.55 \%$ of respondents agreed on the fact that use of ITN can prevent malaria transmission [24].

The finding that one in every four (24.9\%) of the study participants did not correctly identify the mode of transmission is an alerting misconception in the study area. The figure is higher when compared with the report from Iran, where $14.2 \%$ of respondents had misconceptions [22], as well as the report from Botswana, where dirty water and unhygienic surroundings were mentioned as causes of malaria by $12.7 \%$ and $7 \%$ of respondents, respectively [21]. It is also revealed by studies from different parts of Ethiopia, where misconceptions regarding causes, transmissions, and prevention of malaria are very common $[13,15]$.

For instance, in the study of Amahara National Regional State, Ethiopia, exposure to cold weather, hunger, and drinking dirty water were identified as common misconceptions reported as cause of malaria by $25.3 \%, 15.6 \%$ and $14.7 \%$ of respondents, respectively [14].

These misconceptions in the community regarding cause, mode of transmission and treatment can pose challenges to malaria intervention activities. Therefore, the local woreda health office or disease prevention and control department needs to strengthen public awareness creation with due focus to reversing such misconceptions in the community. Overall, when assessing comprehensive knowledge of malaria, $204(50.4 \%)$ of the study participants were having good knowledge level, while 201 (49.6\%) had poor knowledge on malaria. This is lower when compared with a study from Southern Ethiopia, where $74.3 \%$ of respondents had good knowledge while the remaining 25.7\% had poor knowledge [25], but comparable with the study of Pawe District, Northwest Ethiopia, where the overall knowledge score was over $50 \%$, rated to be high [1].

In the current study, 356 (87.9\%) of respondents agreed to sleeping under a mosquito net during the night as a method of preventing oneself from getting malaria. This is slightly lower when compared with the report from Kolla Tembien district, Tigray, Ethiopia, in which $97.55 \%$ of respondents agreed on the fact that use of ITN can prevent malaria transmission [24], but higher when compared with studies from different parts of Ethiopia [14,25]. In this study, 345 (85.2\%) of the respondents correctly mentioned use of antimalarial drugs for treating malaria. On the other hand, 372 (91.8\%) of respondents had positive attitude towards modern healthcare utilization to treatment of malaria. These are encouraging figures when compared with the findings from Amahara National Regional State of Ethiopia and an endemic area of Ethiopia, where $69 \%$ of respondents have positive attitude towards modern health care utilization for malaria treatment [14], and $81.6 \%$ of respondents seek treatment for a febrile disease from health care facilities [18], respectively. On the other hand, misconceptions regarding cause or transmission, treatment and prevention of malaria were reflected from responses provided to attitude questions. In this regard, 63 (15.6\%) of the study participants had misconception on cause and prevention of malaria as they agreed or undecided to the statement that one can prevent him/herself from malaria by avoiding sinful nature or guilty behavior. In the same way, $78(19.26 \%)$ of the study participants had misconception regarding treatment of malaria as they were undecided or believed on traditional 
medicine as treatment of malaria. Despite the finding is consistent with findings from similar studies, for instance in the study from an endemic area of Ethiopia, a sizable fraction of the study participants had misconception and undesirable health seeking behavior [18], it is yet an important indication that there are still gaps on the level of community awareness and perception with regard to cause or transmission, treatment and prevention of malaria and is a useful information to the local health agencies and community health workers in directing appropriate intervention measures. Overall, assessing comprehensive attitude level of individuals, 223 (55.1\%) of respondents had positive attitude and 182 (44.9\%) had negative attitude towards malaria in terms of its susceptibility, seriousness or threat, treatment, prevention and control. This is consistent with the figure in the study from Southern Ethiopia, in which slightly more than half of the respondents $(51.1 \%)$ had positive attitude towards malaria [25], and the study from Amahara National Regional State of Ethiopia, in which $78.1 \%, 69 \%$, and $47.1 \%$ of the study participants were considered as having positive attitude towards malaria prevention, treatment, and good malaria prevention practices, respectively [14].

Regarding practice, it was about $60 \%$ of the study participants that always seek medical care when they or their family member gets sick. This is low when compared with the report from the study conducted in a rural community of Ethiopia, in which $91.9 \%$ of respondents reported use of only modern antimalarial drugs [17], as well as the study from an endemic area of Ethiopia, where $81.6 \%$ of respondents seek treatment for a febrile disease from health care facilities [18]. On the other way, it was observed that nearly $40 \%$ of respondents participated in the current study either look for other options or do nothing for treatment of malaria. This figure is, in fact, lower when compared with the figure reported from a study conducted in Nigeria, in which $47.6 \%$ of respondents reported to have been practicing antimalarial home remedies [20], but it is alarmingly higher than the report from the study from a rural community of Ethiopia, where only $6.8 \%$ of respondents used both modern and traditional medicine, while $1.3 \%$ used only traditional medicine for treatment of malaria [17].

The treatment seeking behavior of the respondents in the current study is discouraging when evaluated against the national malaria guidelines, according to which $100 \%$ of positive malaria diagnoses shall be treated according to the national guidelines, that is Ethiopia has a target of $100 \%$ access to effective and affordable malaria treatment by use of the highly efficacious artemisinin-based combination therapies (ACTs) that are accessible at health facilities across the country $[8,10]$. As to prevention of malaria, about three fourth, 305 (75.3\%) respondents in this study reported that they always sleep in an insecticide treated mosquito nets. This is lower when compared with the finding from the study in Nigeria, where about $80.0 \%$ of the respondents were using bed nets as the most common protective measures against malaria [20], and the study of Shewa Robit town, Northeastern Ethiopia, in which $87.7 \%$ of respondents practiced use of mosquito nets and 59.5\% used house spray with insecticide to prevent and control malaria [16]. However, it is higher when compared with the report from Kolla Tembien district, Tigray region, Ethiopia, in which about $57 \%$ of respondents have reported sleeping under ITNs every night [24], as well as the study of Amahara National Regional State, Ethiopia, in which $26.4 \%$ of participants used ITN as malaria prevention and control method [14]. The figure is slightly lower when compared with the national recommendation, according to which $100 \%$ of households in malaria-endemic areas own one LLIN per sleeping space, and at least $80 \%$ of people at risk of malaria shall use
LLINs $[8,10]$. Overall, when comprehensive practice level was assessed, $274(67.7 \%)$ of the study participants had good practice while 131 $(32.3 \%)$ had poor practice with regard to treatment, prevention and control of malaria. This is encouraging when compared with the study of Amahara National Regional State, Ethiopia, in which $47 \%$ of the total study participants have good practice towards malaria prevention and control activities [14].

Working out associations, educational level was found to have significant association with individual's knowledge of malaria. In this regard, study participants with educational level of College and above were 6 times more likely to have good knowledge of malaria as compared to their illiterate counterparts (AOR (95\% C.I $)=6.377(2.525$, 16.109)) $(\mathrm{p}<0.001)$. This finding is consistent with reports from similar studies conducted in different parts of the country. For instance, according to the study conducted in Pawe district, Northwest Ethiopia, persons who were 9th grade or above were 4.9 times more likely to report a high score of malaria knowledge compared to those who had no formal education [1], whereas in the study conducted in Assosa zone, western Ethiopia, it was revealed that comprehensive knowledge about malaria preventive measures was significantly higher among those who completed college/university [13]. This could be explained by the fact that better educated individuals have better access to information and have the opportunity of better learning and understanding when compared to those with lower educational level or illiterates.

It was also observed that one's knowledge of malaria was found to be significantly associated with his/her attitude towards malaria. Those who had good knowledge of malaria were 3 times more likely to have positive attitude towards malaria when compared to the ones having poor knowledge. On the other hand, one's attitude towards malaria was found to be significantly associated with practice on malaria. Those having positive attitude regarding susceptibility, seriousness and threat or consequences, treatment, prevention and control of malaria were about 5 times more likely to practice good when compared to the one's having negative attitude (AOR $(95 \%$ C.I $)=4.771 \quad(2.885,7.887)$ ) $(\mathrm{p}<0.001)$. These findings could be considered as an interesting implications to the public health practice in the context that positive attitude is enhanced by knowledge, and in turn good practice is enhanced by positive attitude; and which is actually consistent with the theoretical sequence of the three terms commonly presented in various literatures. In the current study, educational level and knowledge of malaria were found to have no significant association with practice on malaria. On the other hand, it was observed in the study from southern Ethiopia, that educational level was significantly associated with ITNs utilization, with $86.7 \%$ of mothers attending secondary education or above having had good practice $(\mathrm{P}=0.01)$ [25], and in the study of Pawe district, northwest Ethiopia, respondent's educational level was significantly associated with treatment seeking habit $(\mathrm{OR}=5.1,95 \% \mathrm{CI}=(2.9-6.2))[1]$.

And in the study of southern Ethiopia, it was observed that women who had good knowledge about malaria and ITNs had relatively good practice of ITNs utilization as compared to those who had poor knowledge [25]. It could be explained from these findings that better educational level and good knowledge of malaria could have significant contribution to ITN utilization or treatment seeking habit in particular, but the effect is insignificant when knowledge and practice are measured comprehensively as it was done in the current study; that is variations with KAP measurement protocols. 
Generally, this study have tried to assess comprehensive knowledge, attitude and practical behavior of the community with regard to malaria treatment, prevention and control in the study area. However, it is merely based on quantitative measures. Failure to consider qualitative study methods could have masked more findings related to cause, seriousness and threat, treatment, prevention and control of malaria, and is considered by the authors as limitation of the study.

\section{Conclusion and Recommendations}

Comprehensive knowledge and attitude on malaria were comparable with most other studies. However, it should be scaled up to achieve the national target that by 2020 all households living in malaria endemic areas shall have the knowledge, attitude and practice towards malaria prevention and control. Moreover, practical behaviors of the community in terms of utilization of appropriate treatment and prevention methods of malaria is slightly low when compared with most studies as well as the national recommendations. Furthermore, there are some misconceptions regarding cause, mode of transmission and treatment of malaria. In this regard, it is recommended that the local woreda health office, disease prevention and control department as well as community health workers need to strengthen comprehensive public awareness creation on causes, mode of transmission, treatment, prevention and control of malaria. Educational level of college and above was positively associated with one's knowledge of malaria. Positive attitude towards malaria was enhanced by knowledge of malaria, and in turn good practice on malaria was enhanced by positive attitude.

\section{Competing Interest}

We authors of this study declare that there is no conflict of interest regarding publication of this study.

\section{Authors Contributions}

All the authors involved in conception and design of the study, coordination, supervision and the overall implementation of data collection. DLK analyzed the data; DLK, DTH drafted and finalized the manuscript DTH, BEB, FBB reviewed the manuscript. All the authors read and approved the manuscript.

\section{Acknowledgments}

We would like to express our gratitude to our data collectors. We appreciate all households participated in this study, we are grateful to heads of households of Areka town or the family members for their cooperation in providing data relevant to this study.

\section{References}

1. Beyene HB, Telele NF, Mekuria AH (2015) Knowledge, Attitude and Practice on Malaria and Associated Factors among Residents in Pawe District, North West Ethiopia: A Cross-Sectional Study. Sci J Pub Healt 3(3): 303-309.

2. World Health Organization (2012) World Malaria Report. WHO, Geneva, Switzerland.

3. World Health Organization (2014) World Malaria Report. WHO, Geneva Switzerland.

4. Peng BI, Tong S, Donald K (2003) Climate Variables and Transmission of Malaria: A 12-Year Data Analysis in Shuchen Country, China. Public Health Reports 118(1): 65-71.
5. Karunamoorthi K, Bekele M (2009) Prevalence of malaria from peripheral blood smears examination: A 1-year retrospective study from the Serbo Health Center, Kersa Woreda, Ethiopia. J Infect Public Health 2(4): 171-176.

6. USAID, CDC (2015) Department of Health \& Human Services: President's Malaria Initiative Ethiopia Malaria Operational Plan FY.

7. Dawit GA, Temesgen TZ, Henry GM (2012) Prevalence and risk factors of malaria in Ethiopia. Malaria J 11: 195.

8. Federal Democratic Republic of Ethiopia Ministry of Health (2012) National Malaria Guidelines. Addis Ababa, Ethiopia.

9. USAID, CDC (2016) Department of Health \& Human Services: President's Malaria Initiative Ethiopia Malaria Operational Plan FY.

10. Federal Democratic Republic of Ethiopia (2010) Ministry of Health National Strategic Plan for Malaria Prevention Control and Elimination in Ethiopia, Addis Ababa, Ethiopia.

11. The Ethiopian Public Health Institute and Partners (2011) Ethiopia National Malaria Indicator Survey. Addis Ababa, Ethiopia.

12. Paulander J, Olsson H, Hailemariam L (2009) Knowledge, Attitudes and Practice about Malaria in Rural Tigray, Ethiopia. Global Health Action.

13. Legesse Y, Tegegn A, Belachew $\mathrm{T}$ (2007) Knowledge, Attitude and Practice about Malaria Transmission and Its Preventive Measures among Households in Urban Areas of Assosa Zone, Western Ethiopia. Ethio J Health Dev 21(2): 12-22.

14. Aderaw Z, Gedefew M (2013) Knowledge, Attitude and Practice of the Community towards Malaria prevention and Control Options in AntiMalaria Association Intervention Zones of Amahara National Regional State, Ethiopia. Glob J Med Res 13(5): 12-34.

15. Alemu A, Tsegaye W, Golassa L (2011) Urban malaria and associated risk factors in Jimma town, south-west Ethiopia. Malaria J 10: 173-180.

16. Abate A, Degarege A, Erko B (2013) Community Knowledge, Attitude and Practice about Malaria in a Low Endemic Setting of Shewa Robit Town, Northeastern Ethiopia. BMC Pub Healt 13: 312.

17. Deressa W, Ali A, Enquoselassie F (2000) Knowledge, Attitude and Practice about Malaria, the Mosquito and Antimalarial Drugs in a Rural Community. Ethiop J Healt Dev.

18. Karunamoorthi K, Kumera A (2010) Knowledge and Health Seeking Behavior for Malaria among the Local Inhabitants in an Endemic Area of Ethiopia. Health 2: 575-581.

19. Departement H (2014) Wolaita Zone Health Department Annual Report, Wolaita, Ethiopia.

20. Singh R, Musa J, Singh S, Ebere UV (2014) Knowledge, Attitude and Practices on Malaria among the Rural Communities in Aliero, Northern Nigeria. J Fam Med Primary Care 3: 39- 44.

21. Chirebvu E, Chimbari MJ, Ngwenya BN (2013) Knowledge and Practices on Malaria in Tubu Village, in a Malaria Endemic Area in Northern Botswana: Implications for Interventions. Malaria J 4: 15.

22. Ahmadi S (2014) Community Knowledge and Practices Regarding Malaria and Long-Lasting Insecticidal Nets during Malaria Elimination Programme in an Endemic Area in Iran. Malaria J 13: 511.

23. Emmanuela EA, Humphrey DM, Heukelbach J (2011) Reported Knowledge, Attitude and Practices regarding malaria and mosquito net use among women seeking antenatal care in southwestern Tanzania. Tanzan J Health Res 13(3): 2-14.

24. Zewdneh T, Tadesse D, Dawit K (2011) Knowledge, Attitude and Practice about Insecticide Treated net usage against Malaria in Kolla Tembien District, Tigray, Ethiopia. MEJS 3(2): 64-77.

25. Terefe GF, Samuel YA, Fiseha LG (2015) Assessment of Knowledge, Attitude and Practice about malaria and ITNs utilization among pregnant women in Shashogo District Southern Ethiopia. Malaria J 14: 235-238. 